\title{
Sofrimento psíquico na universidade, psicossociologia e Encontro de saberes
}

\author{
José Jorge de Carvalho* \\ Makota Kidoiale** \\ Emílio Nolasco de Carvalho*** \\ \& Samira Lima da Costa *
}

\author{
* José Jorge \\ de Carvalho é \\ professor titular \\ de antropologia \\ da Universidade \\ de Brasília (UnB), \\ Brasília, DF, Brasil. \\ Orcid: 0000- \\ 0003-3415-3534. \\ <jorgedc@terra.com. \\ $b r>$.

\section{** Makota Kidoiale (Cássia Cristina da Silva) é líder religiosa do candomblé Angola e representante do quilombo Manzo Nzungo Kaiango e mestra docente do Encontro de saberes na Universidade Federal de Minas Gerais (UFMG), Belo Horizonte, MG, Brasil. \\ Orcid: 0000-0002- \\ 7807-3627. \\ < kidoiale@gmail. com>.}

Brago discute o sofrimento mental e o adoecimento geral da classe acadêmica Encontro de saberes, projeto implantado na Universidade de Brasília, em 2010, que promove a inclusão de mestres e mestras dos saberes tradicionais (indígenas, povos de terreiro, quilombolas, entre outros), como docentes; de outro, uma reconfiguração das ciências sociais como uma área transdisciplinar e pluriepistêmica capaz de dialogar com os sistemas de cura desenvolvidos pelos mestres e mestras tradicionais, que incluem relações com todos os seres vivos (plantas, animais, fenômenos da natureza). O Encontro de saberes da cura faria um diálogo das ciências sociais transdisciplinares antropocêntricas com as ciências tradicionais cosmocêntricas. O texto foi elaborado a quatro vozes: três de acadêmicos da UnB, da UFF e da UFRJ, e uma líder religiosa do candomblé Angola de Belo Horizonte (MG), Makota Kidoiale.

Palavras-chave: Encontro de saberes. Universidade. Conhecimento pluriepistêmico. Saúde mental.

\section{Mental health, psychosociology and "meeting of knowledges"}

Abstract: The article discusses the mental suffering and general illness of the academic class in Brazil, proposing a new an approach to the theme of mental health in two pillars: on the one hand, the "Meeting of knowledges", a project implemented at the University of Brasilia in 2010 that promotes the inclusion of masters of traditional knowledge (indigenous peoples, terreiro peoples, quilombolas, and others) as teachers; on the other, a reconfiguration of the social sciences as a transdisciplinary and multi-systemic area capable of dialoguing with the healing systems developed by the traditional masters, which include relationships with all living beings (plants, animals, nature phenomena). The "Meeting of knowledges in healing" would make a dialogue between anthropocentric transdisciplinary social sciences and traditional cosmocentric sciences. The text was written in four voices: three from academics from UnB, UFF and UFRJ, and a religious leader from Candomblé Angola of Belo Horizonte (MG), Makota Kidoiale.

Keywords: Encontro de saberes. University. Multiepistemic knowledge. Mental health.

*** Emílio Nolasco
de Carvalho é doutor
em antropologia e
professor adjunto
do Instituto de
Psicologia da
Universidade Federal
Fluminense (UFF),
Niterói, Rio de
Janeiro, Brasil.
Orcid: 0000-0002-
0686-5537.
<emiliocarvalho@
id.uff.br>.


**** Samira Lima da Costa é professora adjunta de terapia ocupacional e do Programa de Pós-Graduação em Psicossociologia da Universidade Federal do Rio de Janeiro (UFRJ), Rio de Janeiro (RJ), Brasil. Orcid: 0000-00034891-0436. <biasam2000@ gmail.com>.

\section{Prólogo}

E

ste artigo foi motivado por uma grave crise que se instalou nas universidades brasileiras: o crescente sofrimento mental de toda a comunidade acadêmica, em alguns casos culminando em suicídio entre estudantes, professores e técnicos administrativos. Em um exercício ainda raro de coautoria no nosso meio, construímos reflexões a quatro vozes, três de professores universitários - Universidade de Brasília (UnB), Universidade Federal Fluminense (UFF) e Universidade Federal do Rio de Janeiro (UFRJ) - e a líder religiosa do candomblé Angola de Belo Horizonte Makota Kidoiale, que é também mestra docente do projeto Encontro de saberes da Universidade Federal de Minas Geral (UFMG). Paralelo ao tema trágico do suicídio estudantil, propomos uma retomada e uma reformulação dos impulsos de origem das ciências sociais: integrar as disciplinas para superar a fragmentação epistêmica atual, e tratar a instituição acadêmica não apenas como ambiente autoimune no âmbito do qual se descreve e se analisa o sofrimento mental da sociedade, mas como um dos espaços sociais onde ele é hoje produzido com maior intensidade e onde precisa ser transformado para retornar a uma maior saúde mental.

\section{Introdução: para um Encontro de saberes da saúde mental}

A sociologia como disciplina acadêmica autônoma tem como um de seus clássicos o livro de Émile Durkheim, O suicídio, de 1897. Contudo, uma abordagem fundante e interdisciplinar das ciências sociais, apresentada ainda de um modo conciso e embrionário, pode ser extraída do curto ensaio de Karl Marx denominado Sobre o suicídio, publicado em 1846 e infelizmente ainda muito pouco conhecido.

Marx traduziu uma seleção dos casos narrados por Jaques Peuchet, em 1838, sobre o suicídio na França e intercalou glosas, observações e comentários ao texto extraordinário do arquivista da polícia de Paris, conectando as tragédias que ele selecionou traduzir, com a vida sob o capitalismo, na qual já estava instalado um projeto desumanizador de relações econômicas e sociais que apenas se intensificou desde então, como o atestam os índices alarmantes de doença mental que padecemos nos dias de hoje em escala mundial.

Já na sua frase inicial, o artigo de Marx engloba a todos:

A crítica francesa da sociedade [referindo-se a Peuchet] tem apontado as contradições e os contrassensos da vida moderna, não 
apenas entre classes específicas, mas também em todos os círculos e configurações da hodierna convivência (Marx, 2006: 21).

Em seguida criticou a ilusão dos filantropos

de que se trata apenas de dar aos proletários um pouco de pão e educação, como se somente os trabalhadores definhassem sob as atuais condições sociais, ao passo que, para o restante da sociedade, o mundo tal como existe fosse o melhor dos mundos (Marx, 2006: 21-22).

No que Marx chamou de "restante da sociedade" deve ser incluído também o mundo universitário. À diferença de nós, que nos acostumamos a enxergar a sociedade como um espaço exterior ao nosso mundo acadêmico - a famosa torre de marfim -, Marx nunca foi docente universitário nem pesquisador com estatuto formal, estatal ou privado, e jamais separou a academia de sua leitura crítica geral das instituições sociais ${ }^{1}$.

Ao utilizar um ventriloquismo argumentativo com o texto de Peuchet, Marx alertou que as relações sociais geradas pela sociedade burguesa capitalista, e que incorporou opressões anteriores, como as de gênero (ele foi pioneiro em enfatizar a opressão de gênero como causa do suicídio e do sofrimento mental das mulheres) conduziam a um sofrimento insuportável e insuperável, colocando a alternativa do suicídio como "um notório protesto contra esses desígnios ininteligíveis" (Marx, 2006: 26).

Marx comentou o quadro social e o mundo subjetivo das mulheres e dos homens que se mataram, combinando o olhar sociológico com o psicológico. E como fez emergir também o universo de valores morais e simbólicos que tornaram a vida daquelas pessoas insuportável para elas mesmas ao ponto de renunciar à vida, sua leitura foi também antropológica, se atribuímos a este termo a abordagem cultural dos fenômenos sociais. Na direção contrária desta leitura multidimensional, no final do século XIX três disciplinas se constituíram como academicamente autônomas, a saber, a sociologia, a antropologia e a psicologia, cada uma com o seu objeto de estudo próprio. Contudo, podemos agora recuperar a proposta inovadora de Marx e abordar o sofrimento mental contemporâneo em uma perspectiva inter(trans)disciplinar e integradora.

Apesar de seus inegáveis benefícios científicos para a compreensão de nossa realidade, o modelo de organização do saber acadêmico, consolidado no século XIX europeu e reproduzido no Brasil até o início do século XXI, padece de três dualismos ou parcialidades colonizantes²:

\author{
1. Doze anos após \\ suas reflexões sobre \\ o suicídio, Marx \\ voltou a utilizar o \\ método de análise \\ correlativa entre \\ doença mental e \\ sociedade em outro \\ artigo poderoso, \\ de 1858, intitulado \\ "O crescimento da \\ demência na Grã- \\ Bretanha" (Marx, \\ 2011). \\ 2. Podemos pensar \\ aqui no conceito \\ de dissociação \\ desenvolvido por \\ Samira Costa na \\ seção "Carta da \\ UFRJ: sobre o \\ adoecimento na \\ universidade" deste \\ artigo.
}


i. o monologismo epistêmico, que decreta como único conhecimento válido aquele gerado após a revolução científica europeia, enquanto as epistemologias indígenas, afro-brasileiras, das culturas populares e dos demais povos tradicionais ficaram excluídas de nossas universidades como não científicas;

ii. o dualismo da organização do saber no interior dessa episteme ocidental excludente, que separou as ciências sociais e as humanidades das ciências exatas; e

iii. o dualismo da objetificação, que separa radicalmente o sujeito conhecedor do sujeito a ser conhecido (chamado de objeto das ciências sociais), e que indiretamente retirou a instituição acadêmica do olhar inquiridor dos acadêmicos.

O projeto Encontro de saberes - implantado na UnB em 2010 como resposta a uma demanda dos mestres e mestras para ensinar seus saberes tradicionais nas universidades, e assim contribuir para descolonizar nossos currículos eurocêntricos - favorece que estes dualismos sejam questionados, provocados e, em alguma medida, superados.

Em primeiro lugar, ampliamos o quadro de conhecimento na universidade, que passa de monoepistêmico para pluriepistêmico, ao incorporar as epistemes indígenas, afro-brasileiras e as demais acima mencionadas. Em segundo lugar, superamos a fragmentação institucionalizada do conhecimento em disciplinas isoladas, na medida em que os mestres e as mestras são polímatos, formados em diversas áreas e capazes de transitar facilmente entre elas, sejam elas definidas por nós como ciências, tecnologias, artes ou tradições espirituais. Em terceiro lugar, o Encontro de saberes não opera mais com a relação sujeito-objeto, e os mestres e as mestras não são mais tratados de um modo objetificado, como se fossem informantes, nativos, entrevistados, pacientes, ou quaisquer termos análogos. Pelo contrário, eles e elas são tratados como colegas, parceiros, coautores.

Com elas e eles, o espaço acadêmico passa a refletir sobre si mesmo, pois já não se trata mais de estudar uma sociedade, uma cultura ou um indivíduo que esteja fora do campus. Pelo contrário, o mundo acadêmico passa a ser incluído na sociedade, deixando de ser um espaço considerado como neutro, ou retirado do universo a ser estudado.

Reconhecemos a relevância e a urgência de pensarmos a universidade como espaço de produção de conhecimento sim, mas, mais do que isso, espaço de produção 
de encontros, de vida, de cura. Um espaço de produção de um futuro e de uma sociedade mais plural e menos adoecida. Como veremos nas cartas que se seguem, muitas histórias de tristeza, adoecimento e calamidades são citadas por José Jorge acerca da UnB, por Samira acerca da UFRJ, por Emílio acerca da UFF e por Makota Kidoiale acerca da UFMG.

Este texto foi escrito a quatro vozes em forma de cartas. Ao pensarmos sobre o tema da saúde mental na universidade, Makota Kidoiale - mestra dos saberes tradicionais da cura no terreiro e na universidade, através do Encontro de saberes redigiu as primeiras páginas, que serviram de base para a troca de cartas entre os autores provocados e em diálogo com a mestra.

\section{Carta de Makota Kidoiale: \\ a ciência das kotas que cura}

Meu nome de registro é Cassia Cristina. Sou filha de Efigênia Maria da Conceição. Minha mãe é bisneta de pessoas que foram escravizadas, nascida em Ouro Preto $(M G)$, uma das cidades coloniais que recebeu grande quantidade de negros africanos escravizados. É sabido, embora escondido, que há uma grande influência dos elementos da cultura africana na constituição da cultura brasileira. Os conhecimentos dos povos africanos, mesmo em outras localidades, como ocorreu na grande diáspora, eram transmitidos através da oralidade e da vivência diária na comunidade (terreiro/casa/tradição). Para as culturas africanas, não há conhecimento adquirido que não provenha da vivência prática diária. Minha mãe, conhecida dentro do Axé como Mam'etu Muiande, despertou para seu dom aos 11 anos de idade, quando dá início a seu processo de formação. Apesar dos conhecimentos serem repassados pela oralidade, alguns são específicos para alguns dons ou entidades específicas dominarem. Como o caso da mãe ou do pai de santo, aos quais cabem a preservação dos conhecimentos através das práticas de cura e dos ritos da tradição; as muzenzas, os canbonos, as makotas, entre outros cargos e funções.

No candomblé existem várias funções e cada uma tem um significado dentro da tradição, atribuições específicas, conhecimentos e nomes que indicam sua posição. As makotas, grupo do qual faço parte, tem a função de auxiliar nos trabalhos diretos em dias de toques, e estão na relação mais direta com a mãe de santo. No meu caso, por ser minha mãe biológica, a relação é ainda mais estreita.

Há um movimento em curso nas universidades brasileiras, confluindo com a luta da população negra, com a finalidade de dar visibilidade aos conhecimentos e a seus portadores, que foram ao longo da história negligenciados, soterrados e de- 
monizados. Como parte desse movimento e a história de luta do quilombo que represento - o Manzo Ngunzo Kaiango, em Belo Horizonte (MG) - fui convidada, assim como a minha mãe, a participar do programa de formação transversal em saberes tradicionais.

Desde o meu primeiro dia dentro da universidade, percebi um clima estranho no ar. Deparei-me com jovens e professores adoecidos mentalmente, era só falar dos simples valores que tem a vida no terreiro, que muitos desmoronavam em choro, mais ou menos uns 30\% da turma. Percebi que as kotas do terreiro, que na verdade nada tem a ver com cotas para negros, eram a cura tradicional, indo salvar as ciências humanas. Pois no decorrer dos Encontros de saberes, ao invés de atrair estudantes negras e negros, a gente estava sem perceber acolhendo os brancos, e o mais interessante disso, era a carência em que esses se encontravam. A necessidade de virem até a nós, denunciava uma carga depressiva. Eles - os brancos - estão doentes. Doenças oriundas dos processos de colonialismo, eles se perderam de si próprios, ao tomarem como referência a cultura do colonizador, ainda nos dias de hoje. Nós, mestras e mestres de ofício, percebemos sem precisar abrir livro algum sobre medicina, que se trata de processos de adoecimento da mente adquiridos na busca do suposto saber acadêmico. Nesse sentido, essas pessoas adoecidas precisavam reencontrar-se, e o caminho era a medicina do candomblé. Isso mesmo, o candomblé significa a própria cura do corpo e do espírito em encontro com a sua própria ancestralidade.

Em conversas individuais com alguns dos 30\% brancos, nós, mestras e mestres, constatávamos que a vida já não tinha sentindo. Eu sabia que no silêncio daquele ambiente adoecido, havia um grande número de suicídios, mas a universidade não quer discutir isso. Isso, talvez pelo fato de que, se assim fizer, vai ter de assumir que ela é quem dá a corda, puxa o gatilho, ou empurra do ponto mais alto, com suas exigências de rigores e limites, linguagens e posturas, aqueles que incutiram que este seria o lugar de se tornar uma pessoa considerada como portadora de conhecimentos. Por outro lado, as matrizes de conhecimento dos povos africanos, das quais somos os representantes, até mesmo na luta por sua preservação contra todo tipo de violência advinda de espaços como a academia, oferecemos o próprio chão a essas pessoas adoecidas, que resolveram nos acompanhar a partir do momento que os colocamos em contato com, simplesmente, o chão.

Retornamos com esses para o útero do candomblé, ensinamos a elas como se ensina a uma criança a comer, a rezar, a cantar, enfim, a sentir todo sentimento que um humano pode manifestar, e elas, através dos olhos, nos agradecem, e passam a perceber esses valores. Valores de ser humano, porque aquele lugar que deveria unir a 
inteligência diversa, só adoece as mentes de quem nasceu e esqueceu sua história, porque foram escritas de formas e jeitos diferentes. Nesses espaços se privilegiam "conhecimentos" de outras culturas em detrimento de todas as nossas formas de conhecimento historicamente mantido em confluência com nossas origens e respeito pela terra e os demais seres vivos. Dessa forma, os obrigam a ler e ler, porque se não o fizer, de nada eles vão saber. Mesmo que seu saber seja viver, respeitar, e amar o próximo, isso de nada vai adiantar, se não ler suas histórias escritas e rabiscadas, pelos seus, que muitos dos que escreveram, morreram de loucura, ou de depressão. É triste isso, em razão de uma trajetória de aviltamento de suas bases existenciais. A população negra teve de criar formas de resistência e sobrevivência nesse sistema que buscou e busca incessantemente seu desaparecimento. Estamos passando por esses processos, mantendo nosso espírito de resistência, encarando o racismo e a intolerância em um espaço que adoece para ser doutor. Uma palavra que carrega o significado do dom da cura, mas, por outro lado, cria pessoas adoecidas e desprovidas de bases existenciais sólidas. Há um lapso que não se conecta em algum lugar, que para muitas e muitos é justamente encontrado no contato com as mestras e mestres de saberes.

É urgente que a universidade reflita sobre seu papel na sociedade brasileira. Precisa e deve parar, e compreender que ações como os saberes transversais têm exercido uma função, para além de uma disciplina acadêmica, de uma política pública de saúde mental. Qualquer um pode visitar o terreiro e constatar os 30\% de alunos dessas disciplinas, aqui estão para curar-se. Caso a universidade não assuma essa política, será uma grande contradição, muita ignorância em um espaço que diz reunir conhecimentos e saberes. Todavia, independente de abrir ou não as portas para os mestres e mestras, o candomblé vai continuar com essa missão, seria muito mais fácil caminhar juntos: saberes tradicionais e saberes acadêmicos, assim como a energia chegou aos territórios, seria um avanço também ter os mestres dentro da academia. As mestras e mestres conseguiram enxergar a doença, a academia precisa enxergar esse processo de cura que não se resume meramente à sua inclusão formal em disciplinas nesse espaço, mas da legitimação dessa cultura negligenciada durante os séculos. Quando aceitei o convite para estar aí dentro, aceitei no sentido de entrar, pensando em proteger nossos 30\% de pessoas negras vivas, porém trouxemos para nossos territórios $30 \%$ de pessoas brancas que precisam de cura em razão do estado adoecido em que se encontram. Sem perspectiva alguma de continuar a viver, a universidade não pode mais permitir que a esperança de adquirir conhecimento, um título ou um lugar no mercado de trabalho e status social se torne doença, podendo levar à morte. Conhecimento não adoece, não mata, pelo contrário, atribui sentido à vida, estimulando a convivência sadia com os outros e com a natureza. 
Carta da UnB:

diálogo com Makota Kidoialê na perspectiva das ciências sociais

Como dito acima, Makota foi convidada para dar aulas sobre os saberes do candomblé Angola e detectou um grave problema de sofrimento mental entre os estudantes e professores da UFMG, como ainda em nosso meio. Emílio Nolasco e Samira Costa têm detectado sintomas idênticos respectivamente na UFF e na UFRJ. Quanto a mim, escrevo situado na UnB, instituição atravessada por uma sequência aterradora de suicídios de estudantes nos últimos anos e por um número crescente de casos de sofrimento mental entre docentes e servidores técnico-administrativos.

Já na primeira edição da disciplina Encontro de saberes na UnB, em 2010, convidamos uma mestra raizeira, Lucely Pio, grande conhecedora das plantas medicinais do cerrado. Polímata, como são quase todos os mestres, Lucely não apenas domina o saber farmacêutico, da manipulação dos princípios ativos e das dosagens dos remédios que produz (tinturas, chás, pomadas), como atua também como terapeuta, combinando habilidade sensitiva e intuitiva com escuta atenta, além de dinâmicas individuais e coletivas de sensibilização, colocando todo o seu saber a serviço não da pesquisa impessoal ou mercantilizada da ciência farmacêutica ocidental, mas da cura, da ativação da dimensão espiritual dos estudantes e dos professores que participam de suas aulas. Na última edição da disciplina, em 2018, Lucely concentrou-se explicitamente em preparar remédios para curar os alunos, pois percebeu-os profundamente adoecidos, em todos os planos: fisicamente desenergizados, psiquicamente perturbados, emocional e afetivamente bloqueados e espiritualmente perdidos.

Em todos os seus cursos, Lucely leva os alunos para passear no meio do cerrado virgem para que aprendam a reconhecer as suas plantas amigas. De regresso da coleta, trazem as plantas para a sala de aula, colocam-nas juntas no chão e falam sobre elas e sobre si mesmos. Esse exercício nos torna conscientes de que as plantas são outros seres vivos com quem estabelecemos vínculos. A mestra ensina ainda que uma planta medicinal somente pode curar se tiver suas plantas amigas em volta, para protegê-la, mantê-la saudável e permitir que ela possa liberar o seu poder para curar-nos a nós, seres humanos. Na epistemologia da mestra raizeira, o que cura não é um princípio ativo existente na planta e que pode ser isolado no laboratório, mas uma planta concreta, um ser vivo singular que doa o seu poder curativo para nós em um espaço-tempo também singular. Além disso, em um processo de harmonização interespecífica, Lucely é primeiro curada pelas plantas 
para em seguida tornar possível que elas nos curem. Em outras palavras, a planta é terapeuta de nossa terapeuta, que nos cura com as plantas que a curam e que ela protege com um manejo respeitoso, amoroso e sustentável.

Marcado, então, por um signo não antecipado da presença de saberes sobre a saúde mental e de cura dos acadêmicos, o Encontro de saberes expandiu-se em 2014 para outras universidades, inclusive a Universidade Estadual do Ceará (Uece). O então reitor, um psiquiatra, propôs o tema do Encontro de saberes da saúde mental, e após mútuas ponderações, decidimos abrir a disciplina como Encontro de saberes da cura. A disciplina exemplifica a associação quase imediata que a classe acadêmica começou a estabelecer entre os mestres dos saberes tradicionais e a cura do sofrimento mental. A escolha dos docentes na Uece caiu em dois pajés indígenas, uma mestra de reisado que cura pelas rezas e pelos cantos e um mestre raizeiro que prepara lambedouros e garrafadas. Como no caso da UnB, a disciplina acabou se dirigindo também para a cura dos próprios estudantes.

Assim como a mestra Lucely na UnB e o mestre Eufrásio na Uece, Makota Kidoiale (Cássia Cristina) também identificou um clima similar de adoecimento no ambiente acadêmico da UFMG. Tal como me contou, ela participou pela primeira vez do Encontro de saberes acompanhando sua mãe, Mamêtu N'kise Muiandê (mãe Efigênia), a líder religiosa do candomblé Angola Manzo Nzungo Kaiango. Mesmo sem nenhuma informação prévia sobre a vida universitária, Makota logo identificou o clima de adoecimento entre os alunos e também entre os professores. Quando ocorreu o suicídio de mais um estudante na UFMG, postou uma reflexão sobre suas percepções no seu Facebook, em maio de 2018, que chegou até a mim, e que muito me impactou. Ei-la:

\section{O suicídio de um estudante na UFMG}

Queria falar sobre esses acadêmicos que vêm tirando a própria vida, não sei se tenho o domínio disso, digo da academia, porque da vida essa eu mando bem. Há alguns anos, quando entrei em uma universidade para dizer sobre nossos saberes tradicionais, a minha primeira observação me incomodou muito, parecia que eu estava em uma sala de doentes, onde todos olhavam para minha mãe numa ânsia de se livrar daquele mal, o mais estranho foi que todos eles pareciam com nós, mas suas identidades tinham parado na casa dos avós, e eu fiquei sem entender, porque na rua eles tinham orgulho de estar ali, mas eles pareciam doentes. Então eu comecei a observar o que era aquele lugar, e fiquei pensando nas cotas, falamos que elas estão prontas, mas não estão, as cotas estão prontas para ser burladas, trapaceadas pelos falsos pretos, 
e que esse espaço tem consciência disso, porque quando um jovem negro denuncia, ele é o réu, o prisioneiro de seus próprios direitos, que não são respeitados por essas estruturas organizadas, e dominado pelo sistema que não nos inclui. Não sei se esse jovem era negro, mas me preocupo com nossos (tirando os falsos) negros ali dentro, que quando entra nesse lugar que ao invés de formar pessoas, formam máquinas, para desafiar a própria natureza, e destruir toda tradição desses nossos que antes eu pensava ser orgulho estar nesse lugar, hoje eu tenho medo, por saber que quando nossos filhos entram nessa academia, só entram os corpos, toda sua identidade fica de fora, e que nos povos tradicionais, temos que estar nas portas deste lugar para assegurar que quando nossos filhos saírem, eles possam reencontrar o seu Eu. Porque essa formação acadêmica é uma imposição desse sistema para que ao invés de diploma, saírem de lá com suas cartas de alforria, e é só.

Senhora academia dona dos saberes, mantenha nossos filhos vivos, é o mínimo que você pode fazer para nos comprovar da sua importância. Desculpa a escrita, mas precisava falar.

Como Marx havia feito há 173 anos, Makota Kidoiale percebeu as três dimensões (social, cultural e psíquica) imediatamente, e explicitou a gravidade do suicídio na universidade. E ao mencioná-lo, rompeu com o silêncio da maioria dos acadêmicos sobre a epidemia de autodestruição que coproduzimos e de que padecemos, e cuja responsabilidade ainda não enfrentamos devidamente. Diferente de Marx, porém, que não exerceu como terapeuta, Makota apresentou um caminho de restauração da saúde mental dos alunos e dos professores através da terapia do candomblé. Ao traduzir sua epistemologia de matriz africana para os termos da episteme ocidental, podemos dizer que ela acionou a sociologia do candomblé, a medicina do candomblé e a psiquiatria do candomblé. Essa intervenção epistêmica e terapêutica de Makota nas salas de aula da UFMG deixou mais claro que o saber das mães de santo e dos pais de santo não se limita a uma exposição para os alunos sobre as características culturais das tradições religiosas de origem africana no Brasil, mas engloba uma leitura do sofrimento mental da classe acadêmica e um trabalho de cura e alívio desse sofrimento.

Makota voltou a dar aula em outro semestre e pôde aprofundar o seu trabalho de mestra/docente/terapeuta/líder religiosa, que inclui cura e atendimento dos alunos no seu terreiro. Além disso, ela exercitou com os seus alunos uma terapia motivadora e criativa, que resultou na produção do belo livro, centrado na coautoria dela e de sua mãe, sobre o seu quilombo e a sua comunidade espiritual: Manzo, ventos fortes de um kilombo. Em junho de 2019, encontramo-nos novamente em 
uma audiência pública na Câmara Federal e convidei-a para escrevermos juntos este texto sobre saúde mental e mundo acadêmico. Ela aceitou imediatamente, redigiu estas páginas fulgurantes em poucos dias e eu as passei para Samira Costa e Emílio Nolasco, que combinaram suas intuições anteriores com as reações ao texto de Makota. Lembro que Samira é terapeuta ocupacional e professora de terapia ocupacional e psicologia, e Emílio é antropólogo e professor de psicologia.

Para as ciências dos mestres e mestras tradicionais - sejam indígenas, de religião de matriz africana, quilombolas, caiçaras etc. - a perspectiva é sempre transdisciplinar: a cura do sofrimento mental, isto é, o caminho para a saúde mental, passa por uma reconexão com o cosmos vivo, habitado por todos os gêneros e todas as espécies de seres vivos acima descritos e que sempre dialogam conosco, independentemente de nossa vontade ou consciência. Em outras palavras, somos um ser vivo que quando se afasta de seu equilíbrio saudável, pode ser curado ao recuperar os vínculos positivos com os outros seres, humanos, naturais ou espirituais - ou dito em linguagem não cartesiana, os seres natuespirituais.

Apoiados nos mestres e mestras, podemos ampliar o quadro oferecido pelas ciências sociais acadêmicas e acrescentar que esse modo de vida refém do capitalismo cognitivo faz adoecer a mente, não apenas porque nos compele a estabelecer uma má relação com os outros seres humanos, mas também por uma relação dissonante, desarmônica (incluindo a desarmonia interna gerada pela falta de relação) com os demais seres vivos. Na perspectiva dos mestres e mestras tradicionais de cura, as doenças mentais são consequência dessa má relação estabelecida com os outros seres, tanto provocada pela própria pessoa como pelos outros seres mesmos, por algum motivo que precisa ser desvendado. Claro que Makota, Lucely e os demais mestres e mestras vêm de comunidades onde se exercita intensamente essa relação com todos os seres natuespirituais e também as habilidades de acolhimento e assimilação do outro. Já a nossa comunidade acadêmica atual, deixa-nos carentes de ambos os tipos de relacionamentos e recursos.

Relatos como o de Makota nos obrigam a reconhecer que nossa colonização epistêmica, ao tentar reproduzir esse inalcançável status de eurocêntricos da periferia dos países centrais do Ocidente, se transforma em um problema de saúde mental. Fundir as ciências sociais ocidentais com as ciências tradicionais da convivência (indígenas, de terreiros afro-brasileiros, quilombolas, caiçaras, extrativistas, das culturas populares) é um caminho possível e fértil para inverter essa espiral negativa: da mente colonizada adoecida para uma mente descolonizada e saudável. Com o Encontro de saberes, começamos a exercitar um modo de cruzar essas fronteiras epistêmicas e curar, não a sociedade apenas, que pede ajuda à universidade, mas 
a própria comunidade acadêmica, que não consegue prescrever e trilhar caminhos para a preservação da saúde mental de seus próprios membros - discentes, docentes e técnico-administrativos.

As mães e os pais de santo, as raizeiras, as benzedeiras, os pajés, os xamãs, todos promovem na sala de aula um campo de relações afetivas sempre aberto e acolhedor, eficaz para estimular o desarmamento de mecanismos de prevenção e autopunição. Para os mestres e mestras, ensinar na universidade é curar. E para os alunos - e professores -, aprender dos mestres e mestras é curar-se. A promoção da saúde mental (incluindo a nossa própria saúde mental) deve ser incorporada como um projeto das ciências sociais, e não apenas como um tema de estudo. Para isso podemos - e devemos - contar com os mestres e as mestras dos saberes tradicionais como nossos colegas e parceiros.

Ainda um comentário sobre a brilhante homofonia criada por Makota. Precisamos das cotas com " $c$ " (para negros, indígenas, quilombolas) para curar a doença de nosso racismo crônico, e também anacrônico, quando comparamos o Brasil com outros países de história equivalente de racismo, como Estados Unidos, África do Sul, Índia e Malásia, porém que implementaram ações afirmativas muito antes de nós. E precisamos das kotas com " $k$ " - como Cássia Cristina, Efigênia Muiandê, Lucely Pio, e tantas outras mestras e tantos outros mestres - para curar-nos da doença de um modo de vida acadêmico enlouquecido pela produtividade, competitividade e desconexão com a vida em comunidade e com a natureza. E aqui vem o alerta de Jacques Lacan que ainda não enfrentamos devidamente: o discurso universitário reproduz o discurso capitalista, da mais-valia do capital ao mais-saber da universidade produtivista, com seu mandato escravizante: "Vai, continua. Não para. Continua a saber sempre mais" (Lacan 1992: 110).

Trata-se de retomar um dos impulsos de origem das ciências sociais: a integração das disciplinas, bem como tratar a instituição acadêmica não apenas como lugar autoimune onde se descreve e se analisa o sofrimento mental, mas como um dos espaços sociais onde ele é hoje produzido com grande intensidade. Além disso, trata-se também de acolher os mestres de cura de outras comunidades e tradições epistêmicas (indígenas, de terreiro, quilombolas) que já começam a circular como docentes e que certamente podem ajudar-nos a enfrentar o adoecimento que padecemos e para o qual nós mesmos temos contribuído.

Uma proposta de ciências sociais pluriepistêmicas, transdisciplinares e sociocósmicas, que transcendam o mundo das relações antropocêntricas e que tomem em consideração as relações dos seres humanos em sociedade com os outros seres, 
naturais espirituais como já o fazem os mestres e as mestras das comunidades tradicionais. Estas seriam as bases de um Encontro de saberes. Este encontro, acredito, pode ajudar a curar-nos.

\section{Carta da UFF: \\ "Caríssima dona Makota"}

Li e reli o texto que a senhora fez! E ele provocou em mim uma grande vontade de escrever essa resposta. Agradeço à senhora desde já por isso!

Gostaria de falar-lhe um pouco sobre algumas experiências minhas como professor, alguns afetos e pensamentos sobre a vida docente que seu texto me provocou a elaborar.

Aqui na Universidade Federal Fluminense, onde estou desde 2014, venho me sentindo sendo cuidado e curado pelas amigas e pelos amigos. E desde 2017, quando começou o projeto Encontro de saberes, também pelas mestras e pelos mestres. Sou professor de ensino superior há 22 anos. E venho percebendo, ao longo desse tempo, esse adoecimento de que a senhora falou. Em mim, em meus colegas de trabalho (alguns deles amigos há quase 30 anos!) e em muitos estudantes, principalmente os negros e os cotistas. A universidade é majoritariamente branca entre os estudantes e muito mais ainda entre os professores. Percebo nos cotistas frequentemente uma potência de afirmação que balança aqueles mais conservadores, mas percebo também uma fragilidade de corpo, um desencanto e descrédito e um cansaço progressivos durante a formação. O desânimo cresce por caminhos diferentes neles, em mim e nos meus colegas professores. E vejo os corpos adoecendo na relação não só com a universidade, mas também com a vida.

Ainda não criei um bom caminho para lidar com isso. Vou tropeçando e aprendendo. Frequentemente vejo minhas ações serem engolidas pelas dinâmicas - já banalizadas no dia a dia da universidade - dos colonialismos civilizatórios, dos produtivismos contábeis, do trabalho como prestação de serviço num balcão de venda, da relação com o saber como relação de consumo rápido de informação... Nos momentos mais intensos de desatenção e de cansaço, cada vez mais frequentes, o ensino, a pesquisa, a extensão e a gestão perdem o sentido e a vivacidade.

Tive professores muito bons em minha formação. Daí o começo ter sido cheio de vida. Sou grato a eles, muito mais do que pude expressar pessoalmente! E hoje vejo muitos deles também fragilizados e adoecendo na universidade. Mesmo com isso, e junto, ainda tem muita coisa boa acontecendo ali! 
Ao olhar para a dimensão político-institucional, penso que os professores universitários não conseguiram construir modos mais ativos e participativos de gestão institucional e de participação nas políticas de ensino, pesquisa e extensão. Não somos formados pra isso! Ao longo das reformas universitárias do século XX, consolidamos entre nós um perfil cada vez mais de pesquisador e, por vezes, de educador. Da reforma universitária de 1968 pra cá vimos desaparecer os modelos experimentais instaurados pelos próprios docentes e nos acostumamos com os modelos centralizados nas reitorias e no ministério, cada vez mais voltados para oferecer suporte ao mercado de trabalho e às políticas desenvolvimentistas. O processo foi gradual mas não foi sutil. Tanto a reforma de 1968 quanto as transformações da década de 1990, antes e depois da Lei de Diretrizes e Bases da Educação Nacional (LDB), foram anunciadas, denunciadas em seus efeitos danosos e combatidas. Fizemos greves, encontros, debates. Alguns fizeram greve de fome em Brasília. Ganhamos um pouco mas perdemos em pontos centrais. E nos acostumamos com os danos gerados por estas e novas perdas de lá pra cá. Lembro-me vivamente de uma pensadora, a filósofa Marilena Chauí, falando-nos, na Universidade Federal do Espírito Santo (Ufes), em 1994, apontando os vícios que nos travavam e os desafios a superarmos dentro e fora da universidade. Dizia ela sobre a nossa organização como categoria:

\footnotetext{
O corpo docente universitário tende, por sua vez, a imitar os procedimentos de organização e luta dos trabalhadores industriais e dos serviços, assumindo também a organização e a luta corporativas por empregos, cargos e salários. Ao fazê-lo, deixam as questões relativas à docência, à pesquisa, aos financiamentos e à avaliação universitária nas mãos das direções universitárias, perdendo de vista o verdadeiro lugar da batalha.
}

Não foi só no Brasil. Também na Europa as universidades tornaram-se progressivamente um espaço cada vez mais familiar às lógicas empresariais de mercado e aos interesses desenvolvimentistas do Estado.

Nas universidades federais por onde passei, a grande maioria dos meus colegas não se vê em condições de enfrentar os aspectos mais danosos da instituição universitária e das políticas de educação superior. A maioria de fato não quer esse lugar e essa condição, a não ser que isso gire em torno de seus próprios interesses de pesquisa e produção. Com isso, limitam-se a reclamar quando a dinâmica institucional os atrapalha. Penso que a quase totalidade de nós não teve uma formação voltada sistematicamente para pensar a universidade e menos ainda para participar de sua gestão. Fizemos isso pelas margens. De minha parte, fui formado nos programas de pós-graduação principalmente para a pesquisa; dependendo da área, às vezes para a extensão, pouquíssimas vezes para o ensino. A gestão e as políticas institucionais 
da universidade só chegaram a mim pelas margens da informalidade e pelas conversas com os amigos.

E é nesse ambiente adoecido institucionalmente, despotencializado profissionalmente e, principalmente, hegemonicamente branco que recebíamos antes os estudantes negros e que recebemos mais recentemente os cotistas. É nesse ambiente que as tensões e alianças vão se dando e que a formação acontece.

Não são poucos os professores com os quais convivo que enfrentam esta situação por meios os mais variados em busca de manter unidas a qualidade e a vivacidade do trabalho cotidiano junto aos estudantes: com jeitinho, com arte, com movimentos coletivos, transitando pelos interstícios normativos, pela desobediência civil ou pela sindicalização. Vou tropeçando, dona Makota! Não é fácil fazer valer as resistências no cotidiano da universidade! Os amigos ajudam. Mas a dinâmica acelerada, o imperativo da produção quantitativa, os relatórios periódicos dos projetos, as reuniões de gestão, os editais cada vez mais raros e concorridos internamente, os modos de escrita necessários para publicar artigos, o contínuo subjugo a sistemas de avaliação míopes, medíocres e objetivistas... Tudo isso, com frequência, apequena ou desconsidera parcial ou totalmente as ações que invisto como as mais importantes e valiosas para a formação dos estudantes!

No cansaço contínuo, na aceleração e nas turbulências do dia a dia vamos perdendo de vista nossas condições de cuidadores dos que estão se formando, dos nossos pares e de todos em volta. Vamos perdendo de vista, ora mais ora menos, o cuidado mútuo. E penso que estamos perdendo de vista também as condições básicas para atuarmos como educadores.

Intrinsecamente ligada a essa discussão político-institucional considero igualmente relevante a discussão político-epistêmica. Ao lembrar-me do que a senhora disse e do lugar de onde fala, penso que nós, professores universitários, estamos despreparados para ver e escutar o que os nossos próprios caminhos de conhecimento trazem de adoecimento e desencanto, para nós e para os estudantes ao nosso redor. Há muito tempo separamos as dimensões do conhecimento e da espiritualidade. A grande maioria de nós - e me incluo nisso - não está preparada para olhar e compreender os efeitos desse processo entre Estado, mercado, ciência e cristianismo em nossos corpos e em nossos horizontes de mundo.

Por isso mesmo, acredito que se as dificuldades e violências já são inúmeras para os estudantes negros e cotistas, são ainda mais hostis para aqueles ou aquelas que vêm do terreiro, dona Makota. Em muitas áreas de conhecimento, a universidade 
não está apenas despreparada para pensar o mundo de modo heterogêneo, e menos ainda para dialogar com as formas de encantamento, de magia, de resistência e de afirmação que constituem o terreiro. Pelo contrário, ela foi sistematicamente preparada para o combate e a desqualificação radical dessas formas e desses territórios, que servem frequentemente como objeto de estudo, mas só muito raramente como contrarreferência legítima para o diálogo.

Podemos trilhar esse processo em muitas de suas variações, a partir da história das universidades europeias. Historiadores diferentes, como Jacques Le Goff (2014) e Peter Burke (2003), por exemplo, vêm nos mostrando o quanto a universidade, desde a sua primeira versão europeia no século XI, esteve intimamente ligada à ascensão dos mercadores e dos mercados intelectuais, assim como à consolidação do mercado como forma de organização da vida social. Por outros caminhos, o filósofo Michel Foucault nos ajuda a pensar o quanto a consolidação do Estado de direito, do mercado e da ciência modernos estão relacionados à consolidação do inquérito romano (Foucault, 1999) e à desvalorização das inúmeras formas de pensamento por semeIhança (Foucault, 1995) que permitiam que o pensamento e a espiritualidade permanecessem visceralmente unidos. Foi também nesse mesmo período histórico, entre os séculos XI e XVII, que se deu a demonização e a caça às feiticeiras, às mulheres fortes e aos líderes locais e regionais (Federici, 2017), às deusas, às sabedorias e às práticas mágicas e espirituais dos povos nativos europeus (Ginzburg, 2012). Ao longo desse processo e do século XVII em diante a Europa tornou-se um solo árido, "descampado" de magias, similitudes e espiritualidades nativas. Como nos lembra Silvia Federici, esse período de transformação da Europa produziu também suas caças às feiticeiras na África e nas Américas. Esse processo é inseparável da história moderna de subjugo e genocídio dos povos africanos e ameríndios, e dos povos nativos por todo o mundo. Descartes já havia proposto um descampado algo semelhante em relação a tudo o que havia antes como o único projeto viável para as universidades.

Ao olhar para as linhas constitutivas mais amplas do tempo moderno, fica cada vez mais difícil dissociar a história da universidade das questões modernas do gênero, da raça, da colonização e da escravidão. Só estamos começando a entender e a mapear os efeitos desse processo e a relação dele com o racismo institucional e nossa sociedade e em nossas universidades brasileiras. Sabemos que, ao longo do século $X X$, as universidades brasileiras trilharam um caminho majoritariamente hegemônico e colonial. E não poderia ser de outro modo.

Salvo em algumas áreas e temas pontuais, não construímos de modo afirmativo um estilo brasileiro do intelectual e da formação universitária, como fizeram alemães, franceses, ingleses e americanos. Para mim, uma das marcas do modo colonizado de 
formação do intelectual brasileiro é que aprendemos a viver com pelo menos dois outros em nós: o outro intelectual do dito Primeiro Mundo, que tomamos por referência, e o outro laico, o povo, que tomamos por objeto. Um outro que investimos em ser, mas nunca seremos; e o outro, o povo, que de fato somos, mas investimos em não ser. É um duplo desterramento o tempo todo! Não é geral, claro! Nem é necessariamente determinante de nossos pensamentos e de nossas produções. Penso nisso antes como uma linha estética, entre outras, construída historicamente no meio acadêmico.

As políticas de cotas, impostas em muitos casos de cima pra baixo às universidades, diminuíram consideravelmente as zonas de conforto do intelectual nesse jogo de desterramento. Tratar o outro como objeto tornou-se cada vez mais tenso na universidade. Os estudantes chegaram e vêm chegando por aqui de modo variado. Muitos vêm aprendendo a se coletivizar e a afirmar seus mundos de modo denso, recusando toda e qualquer objetificação de seus mundos. Outros chegam mais discretos. Mas de modos variados as cotas geraram um curto-circuito na relação hierárquica do pesquisador e do seu objeto de estudo. Muitos colegas meus entenderam isso como um adoecimento da instituição. Eu entendo como parte da cura. Mas penso nisso como um processo longo e tenso. Sei bem que o custo é alto pra todos nós, principalmente para os estudantes cotistas, que estão mais expostos e vulneráveis nas tensões hierárquicas. Mais ainda para aqueles que, vindo do terreiro, investem em afirmar seus mundos.

Com tudo isso - a meu ver -, a universidade foi e ainda é uma máquina poderosa de colonização e de extermínio, mas também pode e ainda é uma fonte poderosa de transformação social e de liberdade de pensamento e de expressão. Ainda é um espaço importante de abertura e gestação de novos modos de pensar, de expressar, de novos movimentos sociais e de novas propostas educacionais. Mais ainda nos tempos atuais. E não são poucos os pensadores que produziram ou que estão atualmente produzindo outros modos de ensino, pesquisa e extensão na universidade. Por isso ela ainda me encanta!

No meio de inúmeras experiências e rebeldias, nada tem me encantado mais nos últimos anos do que ver e conviver com a força e a vibração das mestras e dos mestres no projeto Encontro de saberes. É impressionante como essa convivência tem sido curativa para todo o grupo do projeto na UFF e para as turmas de estudantes a cada ano, desde 2017 !

Tal como a senhora falou, os mestres com os quais tive mais contato trazem e afirmam o chão a todo instante. Também aqui na UFF eles nos oferecem o chão de seus mundos como cura para os nossos adoecimentos. Pai Roberto e mãe Márcia 
encheram a sala de folhas, de instrumentos, de cantos e de histórias de resistência e de afirmação de seus povos. Pai Roberto fez um ebó e trouxe para o espaço as boas energias e a proteção dos inquices. Mãe Márcia trouxe as dos voduns. Ogã Kotoquinho e mãe Dadá trouxeram os tambores, botaram a turma para dançar e chamaram para a sala de aula o axé e a proteção dos orixás. Seu Augustinho e dona Marciana trouxeram o coral guarani mbyá, transformando a sala de aula em uma opy para ali conversar com Nhanderu. Dona Dica e seu Altamiro levaram as redes e as cestarias e fizeram da sala de aula um grande espaço de experimentação caiçara. Depois levaram a turma para aulas de campo na mata e no mar para experimentarem com eles as forças encantantes que por lá existem. Seu Manoel Seabra, Toninho Canecão, Fatinha e Luciana trouxeram os tambores e as histórias de seus quilombos, botaram a turma em roda e firmaram o ponto de jongo na universidade. Foi tudo muito forte!

Tal como a senhora e dona Efigênia na UFMG, os mestres e as mestras aqui na UFF ofereceram para nós generosamente o seu chão e, com isso, fizeram da sala de aula um espaço denso, intenso de alegria e de tristeza, cheio de dança e de força, mas também cheio das marcas incontáveis dos extermínios do passado e do presente. Os mestres nos ajudam a redimensionar e a reinventar os nossos modos de lutar. Nós e os nossos jovens universitários, que juntamos de modos apressados os jogos identitários e as fogueiras inquisitórias, estamos todos aprendendo aos poucos com os mestres e com a generosidade deles.

Eu temia que as aulas dos mestres em salas pudessem ser capturadas pelas dinâmicas viciosas da universidade. Enganei-me! Os mestres não se importaram. Muitos até preferiram ocupar a sala de aula. Eu venho percebendo desde então o quanto dou importância demais para essa arquitetura e de menos para a potência dos mundos que a ocupam.

Os mestres trouxeram pra todos nós, por aqui, um caminho novo: a afirmação da potência infinita do chão que nos gera, qualquer que seja o espaço onde se pisa. Sem negar a universidade e a sua história... Sem combatê-los ou confrontá-los. Entendi que afirmando o chão que pisam com toda a sua potência, os mestres não excluem os outros. Nenhum outro! Mesmo os que querem exterminar seus mundos! Pelo contrário, eles investem com todas as forças em trazê-los de volta para o chão, e curá-los! Estou aprendendo aos poucos. Todos nós por aqui estamos. E nós precisamos muito disso!

Agradeço enormemente a eles!

E agradeço mais uma vez à senhora, dona Makota! 


\section{Carta da UFRJ: \\ sobre o adoecimento na universidade}

Já faz um bom tempo venho refletindo sobre as muitas esferas da vida que parecem não caber, ou ao menos não encontrar ajuste na academia. Desde pequena, meu primeiro "desajuste" com a escola foi o fato de preferir andar descalça. Ao comentar em casa, com pesar, que a professora não me permitia ficar sem calçado na escola, ouvi de minha avó:

- Não liga não. Diz a ela que isso é coisa de pescador, o pé no chão e o olho na lua.

Mas parecia que no espaço escolar, não havia lugar para esta parte de mim, neta de pescadores.

Em minha visão, atualmente a instituição escolar, e em especial a universidade, se vê diante da necessidade e da possibilidade de elaborar novas perguntas, novos caminhos, novos referenciais. E é nesse possível que se colocam determinados saberes, em especial aqueles relacionados aos campos da ancestralidade, da espiritualidade, das emoções e do cotidiano integral, fora das compartimentalizações academicamente definidas até então.

Os saberes tradicionais, em cujo âmbito tais esferas não se eliminam mutuamente e não levantam fronteiras de modo excludente, sustentam a inseparabilidade entre corpo, mente, conhecimento, espiritualidade, práticas cotidianas, ciência, filosofia, lazer, trabalho, festividades etc. Sustentam a vida em sua plenitude, em sua integralidade.

Por outro lado, nos estudos acadêmicos, tivemos grandes avanços no que diz respeito a conhecimentos específicos, relevantes para alcançarmos importantes patamares nas diferentes áreas das ciências. Ainda assim, é preciso reconhecer que algo ficou de fora, algo falta. Há um sentido de integralidade da vida que parece não caber muito bem na estrutura do pensamento universitário, que hoje utilizamos como modelo, na produção do conhecimento.

Esta integralidade da vida que vemos em alguns povos tradicionais também pode ser identificada - talvez em menor medida -, na vida cotidiana daqueles que compõem a comunidade acadêmica, mas não compõem o campo da produção do conhecimento. Ao contrário, comumente são aspectos da vida "convidados" a ficar de fora dos processos de produção do conhecimento, em nome de alguma imparcialidade ou impessoalidade - convite difícil de sustentar, se compreendemos que 
os estudos todos são, eles mesmos, completamente implicados com o fazer dos pesquisadores, que, por sua vez, são com eles implicados.

Neste sentido, cabe reconhecermos algumas de nossas limitações. Uma delas, o fato de conseguirmos avançar em especialidades sem, entretanto, encontrarmos a amálgama que permitiria, enfim, reunir os saberes para compreender e melhorar a vida em sua integralidade.

Esta contínua exclusão de determinados campos da vida e sua invisibilização na relação com os processos de produção de conhecimento e daquilo a que chamamos ciência, vem produzindo o que a própria ciência ensaiou chamar "dissociação".

De acordo com o Dicionário Michaelis, "dissociação" é:

1. Ato ou efeito de dissociar(-se); desagregação, desintegração, separação.

2. Na FíSICA e na QuímicA: Processo pelo qual uma molécula se divide em dois ou mais fragmentos.

3. Na PSICOLOGIA: Processo em que os conjuntos coerentes de ações e pensamentos se desintegram, fazendo com que o indivíduo não consiga lidar com fatos ou ideias que naturalmente são conexos; desagregação.

Esta poderia ser considerada uma síntese - embora simplória... - do que nos propõe a academia, em seu modelo fundado no referencial moderno ocidental. A universidade é criada e sustentada para ser a instituição que, voluntária e deliberadamente, promove esta compartimentalização do conhecimento e essa dissociação entre os vários aspectos da vida que a fazem bela, forte e complexa.

Na tentativa de simplificar, ou ao menos ordenar, o pensamento, desagregamos os eixos que juntos dão sentido à existência. De acordo com a definição dada para "dissociação" pelo campo da psicologia, podemos entender que, por desconexão, esvaziamos de coerência os conjuntos de ações e pensamentos que - juntos - criam a complexidade da vida e nossa capacidade de viver. E ao desintegrar conjuntos de coerência e sentido de existência, esta mesma instituição favorece aquilo que ironicamente ela própria identificou, nomeou, classificou... Mas não soube evitar: o sofrimento psíquico.

Deste estado de dissociação, produzido ao mesmo tempo de modo voluntário e compulsório, ao mesmo tempo vindo de fora e de dentro, ao mesmo tempo ati- 
vo e reativo, ao mesmo tempo violento e violentador, se desenham os diferentes quadros de sofrimento, tão tristes quanto comuns, nos corpos que perambulam e constituem a comunidade universitária. Se não se pode, numa mesma instituição, viver o corpo emocional, espiritual, intelectual e comunitário, se é preciso dissociar e "invisibilizar" parte destes corpos ou aspectos da vida, certamente a vida fica mais pobre, mais frágil, mais sofrida.

Nos estudos psiquiátricos, os resultados de grandes traumas e experiências de força, ódio e violência podem levar à dissociação, ou a transtornos dissociativos. Aqui, invertendo o vetor, proponho considerar que a dissociação em si pode ser uma grande violência, aniquilando a possibilidade de sermos todos plurais e vivermos em eixos diversos que convergem. A impossibilidade de evidenciar a óbvia convergência associativa das várias esferas da vida e dos vários corpos que habitamos nos empurra em direção à dissociação e, portanto, ao sofrimento.

A instituição universidade se propõe a esta contínua dissociação dos conhecimentos e dos modos de viver, produzindo empuxo em direção a um lugar-comum acadêmico no qual o ser-pesquisador não existe como vivente-sentinte-pensante, mas apenas como testemunho do viver-sentir alheio ao seu, e parametrizado pelo pensar de outros.

Cerca de dois anos atrás este incômodo me ocupou profundamente. Decidi estudar os modos como se produz e se transmite conhecimento em outros âmbitos fora da universidade. Fiz disso meu pós-doutoramento, decidida a me entregar à relação com algumas comunidades tradicionais com as quais tinha contato, buscando nelas algum sentido nobre para os processos de educação e de produção de conhecimentos. Tenho estado cada vez mais em contato com estas comunidades, em especial as aldeias Guarani Mbya de Araponga, Itaxim e Ara Howy (em Parati e em Maricá, Rio de Janeiro), o Quilombo da Custaneira-Tronco (em Paquetá, no Piauí), o Quilombo do Grotão (em Niterói, Rio de Janeiro) e o Quilombo das Kalungas (em Monte Alegre, Goiás).

Assim, em minha pesquisa de pós-doutoramento, meu movimento era de desencantamento com a universidade. Curiosamente foi o contato com estas comunidades e com suas mestras e seus mestres que me descortinou os olhos, me abriu a visão para aquilo que sempre esteve ao meu lado e favoreceu meu reencantamento com a academia. Após um ano de estudo com estas comunidades, voltei à universidade. Ao tomar emprestados os olhos dos mestres e das mestras, pude ver que nos mesmos laboratórios, nas salas e nos corredores acadêmicos que sustentam esta lógica, reside a semente da criatividade e da resistência às dissociações da vida. Ali 
3. “Quebra a cabaça e espalha as sementes": aula inaugural proferida por Maria Muniz Tupinambá, mestra do Encontro de saberes, no Programa de Pós-Graduação em Psicossociologia de Comunidades e Ecologia Social, do Instituto de Psicologia (UFRJ). mesmo, onde tudo isso parece proibido, é o lugar onde tudo acontece: a espiritualidade, a emoção, o corpo-expressão, a ancestralidade e a intelectualidade convivem e reinventam existências, neste que seria um local árido.

É com este corpo, com este viver-sentir-pensar que leio seu texto, dona Makota. Sinto profundamente a verdade do que a senhora diz: como estamos adoecidos! E dialogando com seu texto, me vejo em processo de cura. A cura está na compreensão dos caminhos que levam ao adoecimento, e a invenção de novos caminhos possíveis.

Olhar para dentro da universidade desde esse lugar que me propus ocupar - um dentro-fora - me fez perceber os modos de andar e pensar a vida, os sujeitos, os coletivos, os valores e as forças que ali se produzem e disputam cenas.

Esse trajeto foi ao mesmo tempo difícil e fácil. Difícil, por constatar todas as estruturas já existentes que habitam tanto os corredores institucionais da academia quanto os corpos e os pensamentos - incluindo os meus. Fácil, por tomar como recurso útil a noção de que a academia nos convida a pensar o que ainda não foi pensado e, portanto, é espaço de liberdade.

Em abril de 2019, tivemos pela primeira vez uma mestra dos saberes tradicionais, dona Maria Muniz Tupinambá, como palestrante em uma aula inaugural de um programa de Pós-graduação da UFRJ ${ }^{3}$. Nesta aula, dona Maria, olhando para professores e estudantes, lamentou a profunda tristeza que via nos olhos das pessoas presentes, e nos orientou a sairmos de casa "com o corpo e a mente fortalecidos", pois o ambiente da universidade estava pesado demais.

Busco, desde então, inventar novas e dar "vida encarnada" a antigas formas de transmissão de saberes e ocupações, na universidade. É fácil olharmos para a universidade e vermos um prédio velho e corrompido, uma instituição arrogante e mortífera. O desafio aqui colocado é, antes de tecer críticas fáceis, olhar de novo, e mais uma vez. Nem sempre se trata de mudar o ponto de vista, o lugar de onde se olha; às vezes é preciso, ao contrário, manter-se no mesmo lugar (no caso, a universidade olhada de dentro), mas mudar o modo como se olha, ou mudar "a vista do ponto" (Gomes \& Merhy, 2014). A partir dos encontros com os muitos mestres, mestras e aprendizes colaboradores desta pesquisa, busco olhar de novo, e de dentro, para a universidade. Para isso, não mudo de lugar; mudo de olhar. Porque esses mestres, ao se colocarem como sujeitos colaboradores da pesquisa, me emprestam também seus olhos, seus modos de ver. E o mundo ganhou outros coloridos. 
Se todos os seres podem ser sujeitos, podem ocupar a posição de sujeito, já não é mais possível estabelecer um só mundo objetivo. Em vez de diferentes pontos de vista sobre o mesmo mundo, diferentes mundos para o mesmo ponto de vista (Sztutman, 2008: 14).

Para isso, entretanto, há de se contar com certo despojamento da academia, certa disposição para esvaziar-se um pouco de si, de modo a abrir espaços onde possam caber os outros. Lembrando Abrahão e coautores,

é necessário sustentar um exercício de desaprendizagem do já sabido, um exercício de desinstitucionalização do prescrito. Um exercício que convoca como parte integrante do processo da pesquisa a problematização e invenção de si e do mundo (Abrahão, Merhy, Gomes, Tallemberg, Chagas, Rocha, Santos, Silva \& Vianna, 2014: 157).

Brincando com as palavras, decido fazer deste estudo uma revisão - uma re-olhada, uma re-mirada. Olhar de novo, e ver outra coisa, usando "óculos de ver acontecimento ${ }^{4}$ "

Com outros modos de ver, vejo nos corredores da academia saberes e práticas encarnadas e cheias de sentido. Crer para ver. Vejo por que creio, aposto que existem, habitam os subterrâneos das relações acadêmicas, produzem composições inovadoras e se manifestam em ondas - ora silenciosas, ora ruidosas - de seus próprios vazamentos.

Identificar nossas raízes acadêmicas no pensamento europeu nos limita, e reconhecer esta limitação nos ajuda e compreender os caminhos para superá-la.

Pensar esses problemas a partir do mundo europeu não é o mesmo que pensá-los fora deste. No Brasil, por exemplo, como em toda a América Latina, a legitimação das formas modernas (científicas) de produção da razão, da verdade e do corpo ocorre num período mais recente. Do mesmo modo, é também recente a marginalização das inúmeras formas outras de produção da razão, da verdade e do corpo etc., encontrando-se esse processo em plena efervescência, na vida social contemporânea (Costa \& Carvalho, 2012: 2933)..

Neste processo de reinventar a universidade, vejo os nossos possíveis. E nos possíveis, nossa cura. Enquanto penso, creio e vejo a cura, não ignoro os sofrimentos à minha volta, a todo tempo... Como cuidar da gente?

\author{
4. Tomo emprestada \\ a experiência do \\ Laboratório de \\ Sensibilidades e \\ Devires, da própria \\ UFRJ - do qual faço \\ parte. Este é um dos \\ muitos espaços- \\ tempos-corpos \\ que se dispõem a \\ olhar a universidade \\ e ver em seus \\ laboratórios, corpos \\ vivos em composição \\ (uma alegoria em \\ contraposição \\ aos laboratórios \\ de anatomia, os \\ mais antigos da \\ universidade).
}


As conjunturas político-econômicas continuamente influenciam e compõem institucionalmente a estrutura acadêmica. Como lembram..., a pauta neoliberal vem há décadas definindo novos rumos para o mundo do trabalho, o que implica duplamente a universidade, por ser campo de trabalho e por ser campo de formação profissional.

\begin{abstract}
Assistiu-se a uma retração financeira do Estado na prestação de serviços sociais (incluindo educação, saúde, pensões, aposentadorias, dentre outros) e a subsequente privatização ou, pelo menos, tentativa de privatização, destes serviços. Assim, a análise do cotidiano dos sistemas educacionais põe a nu alguns vieses bastante graves, a partir da absorção/apropriação das reformas de cunho neoliberal. Tal agenda afeta a cultura escolar, de modo que representações, motivações, normas éticas, concepções, visões e práticas institucionais dos diversos atores, acerca dos objetivos, das tarefas da docência modificam-se e são profundamente mudadas no sentido do individualismo no enfrentamento das situações problemáticas escolares e da vida; do acirramento da competição entre instituições educacionais e entre os pares; da supervalorização das avaliações em escala nacional, com viés pseudomeritocrático, para não dizer meramente classificatório, normativo e punitivo; do imediatismo em relação às demandas do mercado de trabalho; em síntese, ocorre uma construção ideológica, no próprio tecido escolar, nada desprezível, porque miúda, caucionada pelo discurso do mérito, mas pretensiosa nas intenções, na medida em que procura agir fomentando a produtividade, mas desmontando os direitos sociais que pudessem ser ordenados como compromisso social coletivo (Mancebo, Ewald, Prestelo \& Uziel, 2006: 2).
\end{abstract}

Vivemos um momento em que, boa parte das tristezas que vemos nos rostos, corpos, corações e falas acadêmicas, está relacionada à conjuntura do país e do mundo. Estávamos começando a andar com as cotas universitárias, com a expansão do ensino superior, com a revisão de parâmetros escolares e abertura para saberes mais amplos e aterrados, com um cenário que permitiu que o Encontro de saberes fosse possível. A suspensão deste movimento, para muitos de nós, significa tristeza e desânimo. Mas para outros, não é só isso: ao retirar o chão que começava a se firmar, retira-se a própria possibilidade de existência. Pessoas muito jovens, muito sofridas, depositando na universidade sua vida... E sua morte. Ainda que seja possível seguir olhando e vendo, em gestos de resistência, a continuidade da existência de saberes de cura e cuidado pelos corredores da universidade, sei que muitos já não conseguem ver isso. Não conseguem ver nada! Enquanto preparávamos a revisão final deste texto, recebi a notícia do suicídio de (mais) um estudante. Li também a carta de seus colegas, com pedidos simples como: permitam-nos continuar encantados com a academia e com a profissão que escolhemos, ajudem-nos a continuar 
tendo esperança na vida... Uma carta dos estudantes endereçada aos professores. Um pedido de ajuda. Lendo esta carta, me vi comovida com a simplicidade e ao mesmo tempo com a complexidade do pedido. Ao ler esta mesma carta, Makota reagiu imediatamente com a carta abaixo, "A Encruzilhada dos Saberes Acadêmi$\cos ^{\prime \prime}$.

\section{A encruzilhada \\ dos saberes acadêmicos}

Sou quilombola, das tradições de matriz afro-brasileira, resumindo: sou mulher preta de terreiro, falo assim porque me vejo muito diferente de quem também está nesse lugar, essa diferença deve ser porque eu fui gerada e parida dentro do terreiro, eu devo ter alimentado das energias das entidades que minha mãe recebia quando ainda grávida de mim, ou também pode ser o pai Benedito que por ser um curador, me escolheu para ajudar outras pessoas.

Bom, o que quero falar mesmo, é da minha experiência na Universidade Federal de Minas Gerais, e esses caminhos que muitas vezes têm levado à morte: a encruzilhada dos saberes acadêmicos.

Não sei quantos anos tem esse porão. Porque o que vejo nesse lugar é isso, um porão, e como imaginar uma encruzilhada dentro desse lugar?

Chamam de saberes acadêmicos, os doutores, mestrandos, os docentes, estão todos nesse porão, tendo que achar caminhos em meio do nada, muitos cavam, perduram, constroem pontes, máquinas, invadem territórios, queimam florestas, criam conselhos, e cadeiras, tudo isso pra quê?

Tem também a gente ali dentro, que, para reconhecer o que sabemos, só agora permite através do "notório saber" eu ainda não sei o que significa, mas sei que meu saber me veio dos meus antepassados, porque trago tudo na memória, como se alguém me deixou escrito aqui, dentro de mim mesmo.

Mas voltando lá no conhecimento acadêmico...

Chegamos no fim, e agora?

Que rumo tomar, dentro de um porão?

É preciso chamar os "notórios saberes", só eles sabem a direção que se tem uma encruzilhada dentro de um porão. Meu Deus, os saberes acadêmicos estão empurrando os seus discípulos ao mar aberto, estão destruindo o planeta, matando a terra, e nos

5. "Notório saber" é o título concedido pelas universidades, em caráter excepcional, equivalente ao de doutor, para os professores que ainda não o possuem. $\mathrm{O}$ Encontro de saberes reivindica este título para os mestres e mestras que já foram docentes nas universidades. A UFMG aprovou recentemente a resolução que permitirá a outorga do título, em um primeiro momento ainda de um modo genérico, sem menção dos mestres do Encontro de saberes desta universidade. Sobre a fundamentação do "notório saber", ver Carvalho (2016). 
diz "Reconhecei a verdade, e a verdade vos libertará", é isso mesmo professor? Eu pergunto porque tem gente minha aí dentro, gente essa que está sendo lavada novamente, para ter permissão de estar em qualquer outro lugar, não torture mais o meu povo, e se não quiserem os seus, a gente acolhe aqui também, podem direcionar ao nosso território, em tratamento de cura da tortura e da humilhação, nós sabemos curar, a universidade não quer abrir mão da sabedoria que só domina o saber de escravizar, e se não permitimos fazer aos nossos, fazem aos seus.

Fuja também, professor, não deixe que você assuma a culpa de torturador, vamos proteger a terra, só ela é a "verdadeira verdade que salvará", esta é a saída desta "encruzilhada de porão".

\section{Epílogo}

Na academia é assim: avançaremos, chegaremos até um ponto. E então precisaremos dos mestres e das mestras, porque vão além.

Apresentamos aqui a proposta de uma área de ciências sociais pluriepistêmica, transdisciplinar e sociocósmica, capaz de transcender o mundo das relações antropocêntricas e tomar em consideração as relações dos seres humanos em sociedade com os outros seres, naturais e espirituais, como já o fazem os mestres e as mestras das comunidades tradicionais. Estas seriam as bases de um Encontro de saberes das ciências sociais antropocêntricas com as ciências natuespirituais cosmocêntricas dos mestres e das mestras. Este encontro - acredito - pode ajudar a curar-nos.

Que o diálogo que iniciamos aqui e agora com Makota Kidoiale possa ampliar-se, com ela e com outras mestras e outros mestres, conosco e com outros colegas nossos, da UnB, UFMG, UFF, UFRJ, e de outras universidades que acolhem as mestras e os mestres dos saberes tradicionais do cuidado com a saúde mental.

\section{Referências}

ABRAHÃO, Ana Lúcia; MERHY, Emerson Elias; GOMES, Maria Paula Cerqueira; TALLEMBERG, Claudia; CHAGAS, Magda de Souza; ROCHA, Monica; SANTOS, Nereida Lucia Palko dos; SILVA, Erminia; VIANNA, Leila. O pesquisador IN-MUNDO e o processo de produção de outras formas de investigação em saúde. In: GOMES, Maria Paula Cerqueira; MERHY, Émerson Elias (Orgs). Pesquisadores IN-MUNDO - um estudo da produção do acesso e barreira em saúde mental, p. 155-170. Coleção "Micropolítica do Trabalho e o Cuidado em Saúde". Porto Alegre: Rede Unida, 2014. 
BRITO, Janaina Madeira; BARROS DE BARROS, Maria Elizabeth. Prática de pesquisa e saúde docente: a narratividade como estratégia metodológica. Revista Psicologia e Saúde, v. 6, n. 2, p. 38-46, Jul./Dez. 2014.

BURKE, Peter. Uma história social do conhecimento I: de Gutenberg a Diderot. Rio de Janeiro: Zahar, 2003.

CARVALHO, José Jorge. A Escola de Kyoto, a filosofia ocidental e as artes indígenas amazônicas. Triálogo para a construção de um Encontro de saberes filosóficos. In: GIACOIA JR., Oswaldo; FLORENTINO NETO, Antonio (Orgs.). Ciência e arte na Escola de Kyoto. Campinas (SP): Editora PHI, 2019.

. Encontro de saberes e descolonização: Para uma refundação étnica, racial e epistêmica das universidades brasileiras. In: BERNARDINO-COSTA, Joaze; MALDONADO-TORRES, Nelson; GROSSFOGUEL, Ramón (Orgs.). Decolonialidade e pensamento afrodiaspórico, p. 79-106. Belo Horizonte: Autêntica, 2018.

— Uma proposta de estudos culturais na América Latina: inclusão étnica e racial, transdisciplinaridade e Encontro de saberes. In: ALMEIDA, Júlia; PATROCíNIO, Paulo Roberto Tonani do (Orgs.). Estudos culturais: legado e apropriações, p. 157-189. Campinas: Pontes Editores, 2017.

— Sobre o notório saber dos mestres tradicionais nas instituições de ensino superior e de pesquisa. Cadernos de Inclusão, n. 8. Brasília: Instituto de Inclusão no Ensino Superior e na Pesquisa/UnB, 2016.

CARVALHO, José Jorge; ÁGUAS, Carla. Encontro de saberes: um desafio teórico, político e epistemológico. Em: SANTOS, Boaventura de Sousa; CUNHA, Teresa (Orgs.). Colóquio internacional epistemologias do Sul, v. 1: "Democratizar a democracia”, p. 1017-1027. Coimbra: Universidade Coimbra; Centro de Estudos Sociais, 2015.

CARVALHO, José Jorge; FLORES, Juliana. The meeting of knowledges: a project for the decolonization of universities in Latin America. Postcolonial Studies. Special issue: "Decoloniality, knowledges and aesthetics", v. 17, n. 2, p. 122-139. Melbourne (Aus): Institute of Postcolonial Studies, June 2014.

— . Encuentro de saberes: proyecto para decolonizar el conocimiento universitário eurocéntrico. Nómadas, v. 41, p. 131-147, Bogotá (CO): Universidad Central, Out. 2014b.

CHAUÍ, Marilena. Ética e universidade. XLVI Reunião Anual Da SBPC. Vitória (ES): 1994 (mimeo). 
COSTA, Samira Lima da; CARVALHO, Emilio Nolasco de. Agentes comunitários de saúde: agenciadores de encontros entre territórios. Ciência \& Saúde Coletiva, v. 17, n. 11, p. 2931-2940, 2012.

DURKHEIM, Émile. O suicídio. São Paulo: Martins Fontes, 2000.

FEDERICI, Silvia. Calibã e a bruxa: mulheres, corpo e acumulação primitiva. São Paulo: Elefante, 2017.

FOUCAULT, Michel. A verdade e as formas jurídicas. Rio de Janeiro: Nau Editor, 1999. . As palavras e as coisas: uma arqueologia das ciências humanas. São Paulo: Martins Fontes, 1995.

GINZBURG, Carlo. História noturna. São Paulo: Companhia das Letras, 2012.

GOMES, Maria Paula Cerqueira; MERHY, Emerson Elias. Pesquisadores IN-MUNDO: um estudo da produção do acesso e barreira em saúde mental. Porto Alegre: Rede Unida, 2014.

LACAN, Jacques. O Seminário. Livro 17: "O avesso da psicanálise". Rio de Janeiro: Zahar, 1992.

LE GOFF, Jacques. Para uma outra Idade Média: tempo, trabalho e cultura no Ocidente. Petrópolis (RJ): Vozes, 2014.

MAMETU N'KISI MUIANDÊ; MAKOTA KIDOIALE Manzo, Ventos fortes de um kilombo. Belo Horizonte: Associação de Resistência Cultural da Comunidade Quilombola Manzo Nzungo Kaiango, 2018.

MANCEBO, Deise; EWALD, Ariane P.; PRESTRELO, Eleonora Torres; UZIEL, Ana Paula. Em discussão: o trabalho docente. Estudos e Pesquisas em Psicologia, Ano 6, n. 1, , p. 1-5, Rio de Janeiro: UERJ, 2006.

MARX, Karl. El aumento de la demencia en Gran Bretaña. In: MARX, Karl. Acerca del suicidio, p. 117-124. Buenos Aires: Las Cuarenta, 2011.

. Sobre o suicídio. São Paulo: Boitempo, 2006 [1846].

MICHAELIS, Dicionário Língua Portuguesa. Versão online Michaelis. Disponível em: <http://michaelis.uol.com.br/busca?id=ZnzA>. Acesso em: 17 Set. 2019.

SZTUTMAN, R. Encontros: Eduardo Viveiros de Castro. Rio de Janeiro: Azougue Editorial, 2008. 